\title{
How to build a geodesic dome An overview and introduction for construction of geodesic domes in a simple word in addition with studding a case and designing a Research Center with this structure
}

\author{
MARYAM GHORBANZADEH \\ Department of Architecture, Faculty of Art, University of Bojnord, Bojnord, Iran. \\ http://dx.doi.org/10.12944/CWE.11.Special-Issue1.08
}

(Received: July, 2016; Accepted: August, 2016)

\begin{abstract}
Geodesic dome is a spherical structures that is formed of five Platonic geometry used in construction, although apparently the dome has complex geometry, they have quick and easy way for constructing. In this paper, how to build a simple dome Geodesic is described in a simple word, which says the possibility of holding it in any space and with any little materials is possible. Geodesic domes offer us much architectural features, at the end of this article, a research center within this volume is designed by the author and the described manufacturing method -described in the paperhas been used for its construction.
\end{abstract}

Keywords: Geodesic dome, fast construction methods, features, case study.

\section{INTRODUCTION}

Geodesic dome is a space type of structure that looks like a section of a ball or sphere. This instrument is made of a grid of triangles that eventually form a spherical surface. The greater the number of triangles the better form of a sphereshaped dome is approached. (Urner, 2016) The using hardness and stability of triangle will cause the strength of dome and integration of the parts spreads the force in all the sphere so finally the geodesic dome makes an efficient structure.

In geodesic domes -that are formed based on 5 Platonic solids-, the icosahedron is mostly used.

Geodesic domes have the highest proportion space in interior to exterior, and so have the minimum levels for heat loss, and in such structures all structural parts evenly spread forces.
There are different sizes of triangles in a geodesic dome that depends on frequency of divisions of multi-faceted lower parts which all the vertices of the triangle is located approximately on the sphere. Cross-section of a geodesic dome is almost a big circle.

Buckminister Fuller is known as the inventor of geodesic dome.

In the picture bellow the phases of constructing a geodesic dome is presented that we continue the article on how it is made.

Geodesic domes are of efficient structures, due to the minimal use of materials they have light weight and they cover large spans in comparison with thin layer.

Quick and easy installation and dismantling of the structures and because of the shape of a 
sphere they stand strong against the stationary high winds. Because of the structural advantages of the dome and their appeal forms, they can be very useful today if we get familiar with the technology, manufacturing and installing these structures. This article offers an general introduction of domes for non-specialists and describe their installation in a simple way. At the end writer offers a project according to this structure is offered.

Headlines of this article are as follow:

1. Introduction

2. History

3. Geodesic Domes advantages

4. How forces are transmitted in a dome?

5. How can we build a geodesic dome?

6. Case study: UK Garden of Eden project

7. Designing a Research center with geodesic dome

\section{CONCLUSION}

\section{History of geodesic dome}

The first dome that can be considered as geodesic was designed by Walter Bars Feld and it was to accommodate a planetarium projector, that this design was conducted as Zeiss factory roof by Wydmann \& Dykerhoff in Germany it opened in 1922. Almost 30 years later, in 1954, Buckminster Fuller $^{1}$, American geological materialist proposed the seemingly independent idea of the domes and called it "Geodesic Dome".

However, in many books he is known as the inventor of the geodesic dome. He first designed this dome, 17 meters high, for DOD at elevations that its wind speed reaches 360 kilometers per second, accessing to this technology which was during the Cold War led to president Nixon's claim that: "We can create a roof on all American cities".

During the time of Fuller other things were done with these structures, such as a concert hall for 1800 people was built in 48 hours!

Invention of geodesic dome was by the Buckminster Fuller that took almost 20-year effort to build for, this invention was a brilliant display of his principles about energy and force, and in fact, the invention can solve many problems in building.
Charm and speed of construction was the reason for the development of these structures. (Ghorbanzadeh, 2008)

\section{Geodesic Domes advantages}

Domes are extremely robust structures that actually as they grow bigger they become stronger, it is the opposite of what normally occurs in construction. (Wikipedia, 2015)

Geodesic domes main structure can be very fast installed in just a few hours instead of months or years of and lightweight parts that can be installed by small screws, with large domes 50 meters in diameter with minimal materials and are possible to construct with minimum of workshop equipment like crane, in addition to these domes have aerodynamic form that can withstand very strong winds. There are no evidence proving that there was ever a problem with these structures nor damage created by wind and typhoons to the domes that are designed in a good way. (Baldwin, 2015)

Sun's energy can be used if we use the transparent covers.

Earthquake can never cause damage to the structure, unless earth break up and swallow the whole building! Or the dome starts breaking in parts from the lower layers such as the dome of South Pole.

The main advantage of geodesic domes is their curvature that allows the sustainability of them in a single layer to cover a large place with a very thin layer.

There are debates of using aluminum in these structures today which creates the resistibility to acidic environment that will also be the stainless structures while its low weight is doubled. (Ghorbanzadeh, 2008)

Today, many companies sell maps and materials of the dome installation so that the buyer can build it themselves. (Wikipedia, 2015)

Indeed, the geodesic domes are a symbol of this slogan "More with less" That Buckminster 
himself applied the term "Ephemeralization". (Baldwin, 2015)

Finally we should mention that while the geodesic dome structures are profitable structures, they are also of great architectural appeal.

Generally geodesic structures have the following advantages:

1. The speed and accuracy because of factory made parts

2. Ability to remove and reinstall

3. Ability to repair and easy maintenance

4. Independence from installation to weather conditions

5. Ability to run in different colors

6. Usability indoors -Like booth inside exhibitions-

7. Resistance to corrosion

8. Economically acceptable- for minimal use of installment-

9. Usability of solar energy

10. Ability to cover large spans with a minimum thickness

\section{How to transfer forces}

Geodesic dome, is a spherical space frame structure, which loads are transferred to stays via linear parts which are in the spherical dome and all parts are under the equal tension (pull or pressure) [5]

All Parts that are located on top of the hemispherical dome under the uniform load which in on the sphere, are under pressure and all lower parts are under the tension and all close vertical parts are under pressure.

Geodesic dome does not have to be a perfect sphere, it can be a huge part of sphere, hemisphere or a little part of sphere. (Ghorbanzadeh, 2008)

If the geodesic dome is a hemisphere, it greatly reduces buoyancy forces are almost equal to zero because the bearings are placed against each other.

If geodesic dome is $1 / 4$ (one-fourth) of the sphere, 5 points relies and buoyancy forces on foot dome in this case high buoyancy forces will get towards the outside.
If geodesic dome is $3 / 4$ (three-quarters) of the sphere it still have 5 points which can rely on and buoyancy forces are inward and also intense. (Ghorbanzadeh, 2008)

In terms of structural constructing geodesic domes are far beyond the traditional methods of construction (vertical beams and columns). Traditional methods of constructing structures are very inefficient because of high materials with high volume and low static use.

\section{How can we make a geodesic dome?}

For the formation of a regular compound that is made of different parts and in order to keep their vertices on a sphere, not every shape can be used, geodesic domes are formed by five single shape Platonic size: triangular or threedimensional, cube or four-dimensional, octagonal or 8-dimentional, twelve-sided or 12-dimentsional, 20 sided or 20-dimensional. (Moore, 2008)

In this 4 volume all polygons are regular and all sides are the same and the number of dimensions is equal to the number of vertices.

The best-known form of a geodesic dome is a soccer ball that is made by dividing the repeat triples of the twenty-sided volumes.

Then we have tried to build a really simple geodesic dome with pretty simple materials and a little reed, adhesive. (Jonathan, 2015) For this purpose, light bamboo is used that you can still use it to make a dwelling in the garden. This structure is lightweight so that you can even teach it to your children to have it in an hour.

The structures is climbing shaped which means it is arranged from bottom to top and grows from the ground, about 35 pieces of bamboo with a length of about 4 feet (about $121 \mathrm{~cm}$ ) is needed to be marked with red stripes and will help to establish the dome.

Small straw is about 3 feet and 6 inches (about 106 centimeters) long and marked with a blue bar. (In Printed picture they are black and white, blue Canes are stronger in color more than red Canes) 
It is noteworthy that can be bigger or smaller building structures but it is important to note that the size of the small parts is approximately $11 \%$ smaller than the big parts greater.

Because the structure relies on its parts it is necessary that almost all parts have, 0.5 Inch (1.3 $\mathrm{cm}$ ) thickness.

Constructing the dome is very easy, shapes are drawn very simply so the constructing would get easy, although this does not mean that constructing it would be easy.

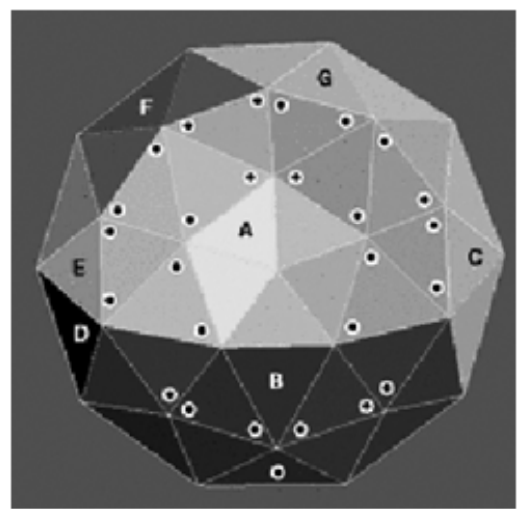

Fig. 1: Combine hexagons to build geodesic dome
The picture below shows the location of red and blue straw in the dome of the plan, (in print black and white, blue Canes are stronger in color than red canes)

Step 1: The first thing you do is placing 10 red straws of the circular next to each other and linking them.

Step 2: This stage is when you build first triangles that will make the geodesic doom, in this way that at the end of each of the 10 straw that you made before a pair of straws is connected, the straws are matched together so that they are red and blue one after another. There is no need to height from the ground.

Step 3: At this stage, connect the triangle with vertices together high from the ground level, use blue straws.

Step 4: At this stage triangles of second step are connected together. This is done that if you look at the doom from above, a red star should be seen. Supportive straws are blue and star straws are red.

Step 5: At this stage, approximately dome began to take shape, at this section you will make a 5 sided shape with red straws together to build the vertices of the star.

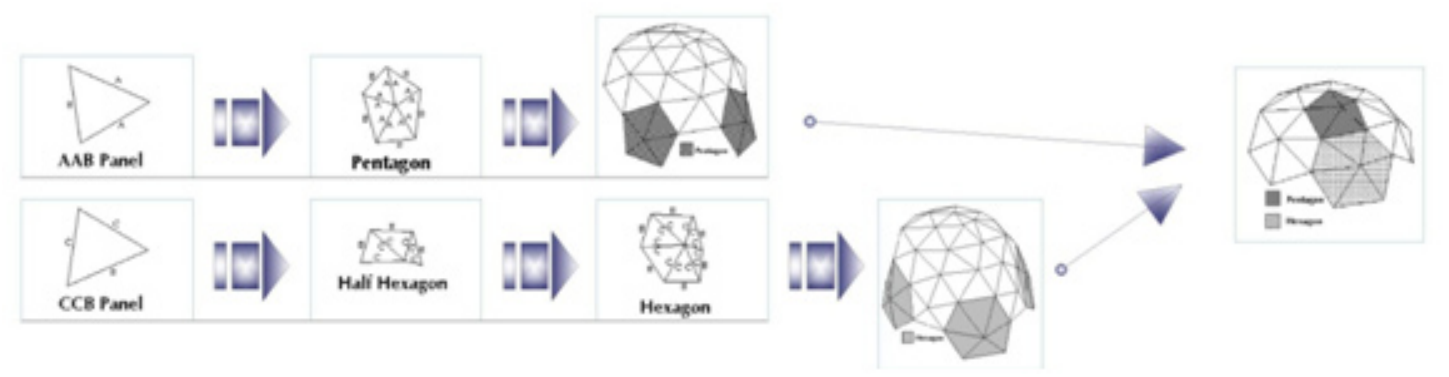

Fig. 2: How to build a geodesic dome with combining hexagons and pentagon
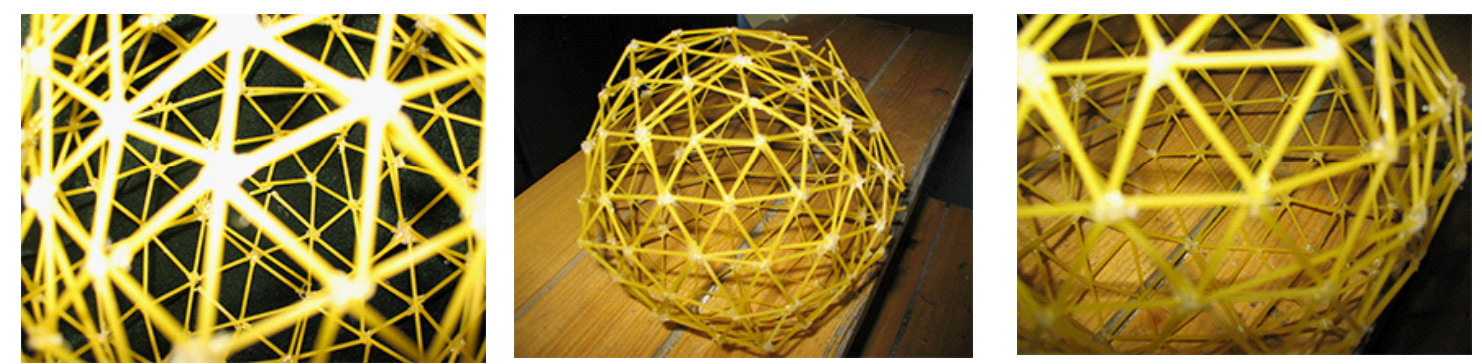

Fig. 3: Pictures of geodesic dome's replica, author 
Step 6: Splendor time! High blue roof is installed, to use blue straws in the center of the circle to connect them together, the straws are used to connect to vertices of 5 sides.

This method that was implemented in six phases, has created an interesting and beautiful structure, beauty of a geodesic dome is that when parts are properly installed a rigid and strong structure is created.

The final stage is covering the dome that can be done with foil, the use of aluminum sheet is lighter weight and additionally polymer coatings such as ETFE (Ethylene tetra-fluoride, ethylene) are used that are waterproof and lightweight. (Ghorbanzadeh, 2008)

1. A case study of a project run by Geodesic Structures (The Eden project (Cornwall, UK))

Name of the project: Eden Location: Cornwall, England

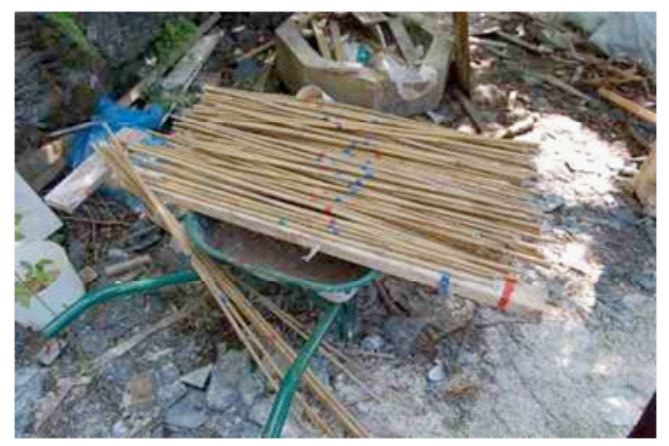

Fig. 4: you can build a geodesic dome with some straws in your garden(Jonathan, 2015)

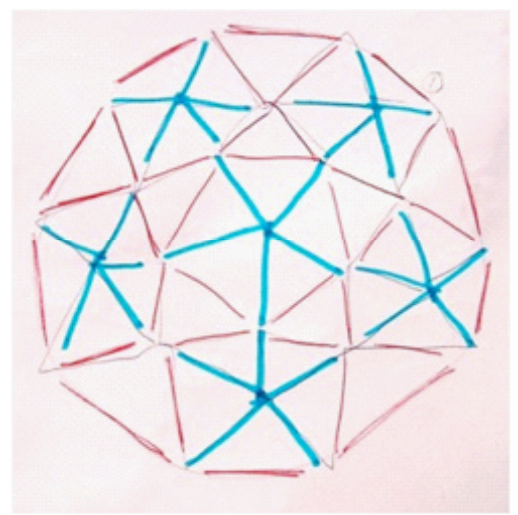

Fig. 5: Pictures of a geodesic dome form above, (Jonathan, 2015)
Completion date: 2001

Size: 23000 square meter (247480 square foot) Structural Engineer: Engineers of Anthony Hunt Services Engineer: Arup Cost Consultant: Davis Langdon \& Everest Prime contractor: McAlpine Joint Venture Landscape Architecture: Consultants of Land Use (Grimshaw, 2015)

Eden Project, is an exhibition to show the diversity of plants in the world. It is a geodesic dome structures.

The project is one of the newest places for this purpose that in shape and form in the last millennium seems very innovative.

The project, is the largest greenhouses and storage for compartment of plants in the word that is also constructed in the clearest and most beautiful at the same time the most economical way possible.

Nicholas Grimshaw and Partners Company get to negotiations for the designing of this project in 1996 with the reputation which was obtained from the Waterloo International Terminal project design. It was also done by Grimshaw.

In prototype designing the spiral and asymmetric shape of Waterloo beam was inspired which was useful by the Finance Commission of the Millennium.

However, during the detailed design had undertaken some little changes, due to uneven seabed pits (which was still like a mine in the

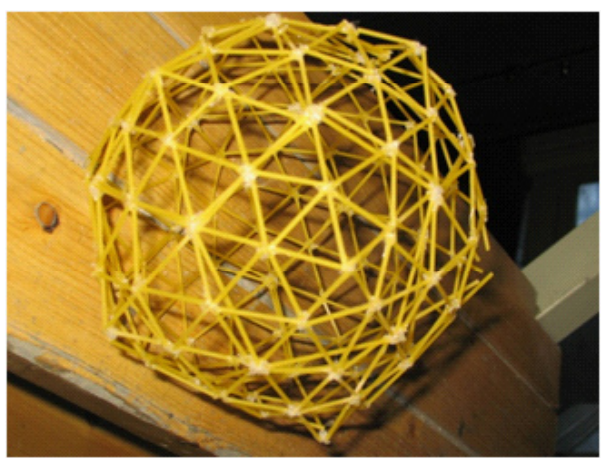

Fig. 6: Replica of the presented project at this article, author 
early stages of designing the project and was not subjected to significant changes) couldn't easily adapt to different arcs, and the diverse span. Now that the project is completed, in terms of image and dreams of geodesic dome inventor Buckminster Fuller this project will offer maximum capacity on the ground surface that is really minimal.

Spheres in the appearance are random string of seven geodesic dome with the internal
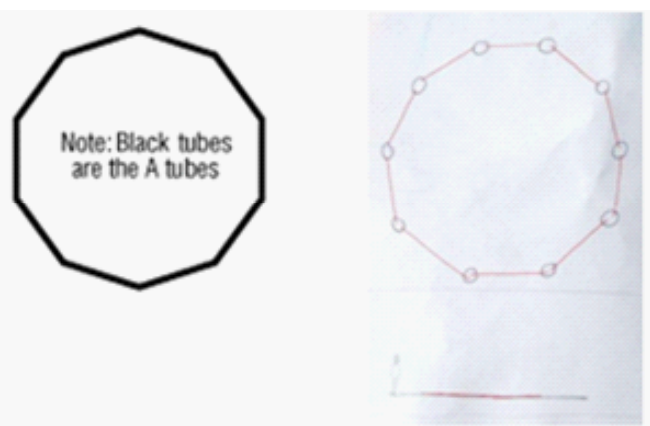

Fig. 7: creating outer circles with red straws
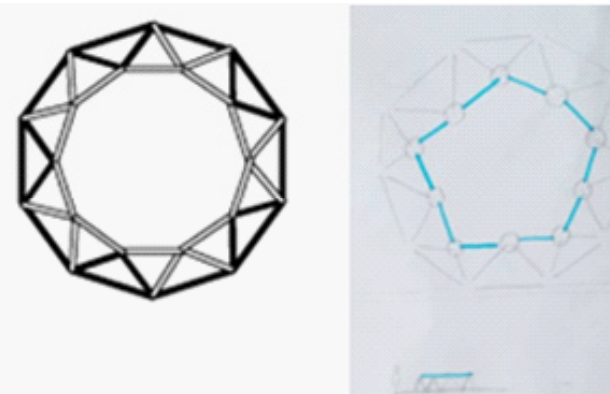

Fig. 9: Connecting vertices of the triangles
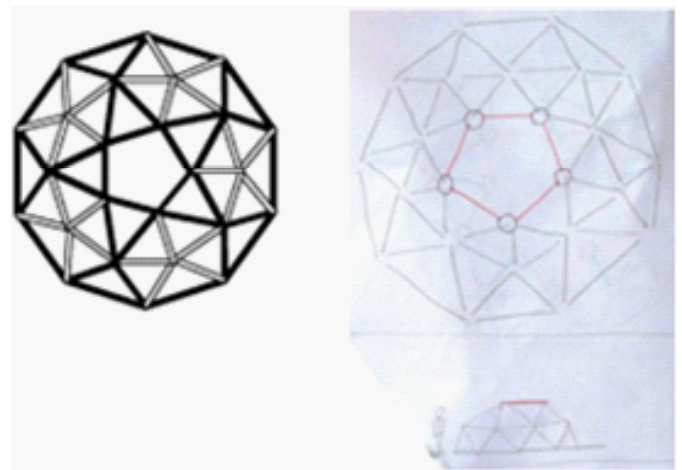

Fig. 11: creating pentagon above upper triangles connection established in the ground and they covered a territory of about 2.2 hectares of the site.

These balls have different radius are to be useful for the life of plants with different heights from 18 to 65 meters.

Form follows function, a tangible expression of the general purpose of the employer to show globally that human's life depends on the plants.
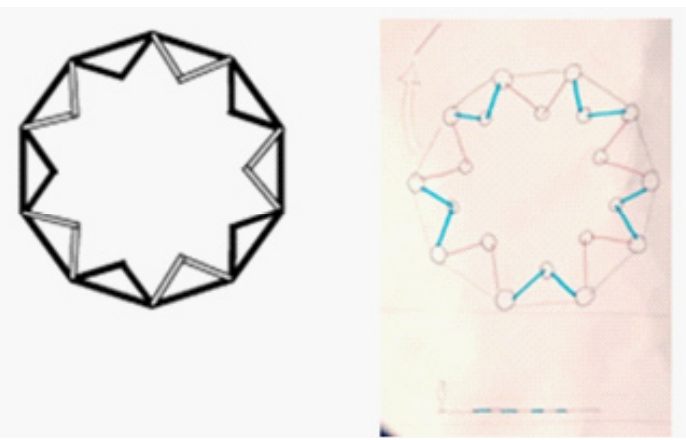

Fig. 8: building first parts of the triangle

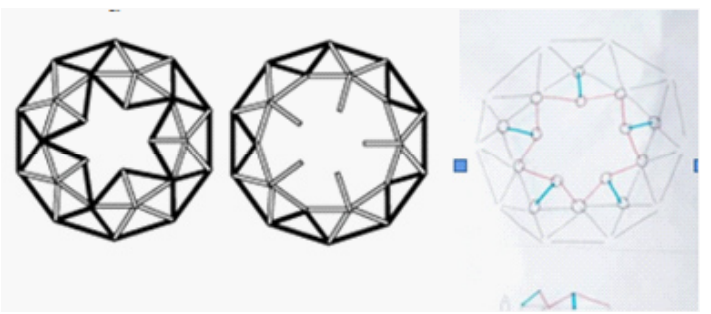

Fig. 10: creating the upper triangles
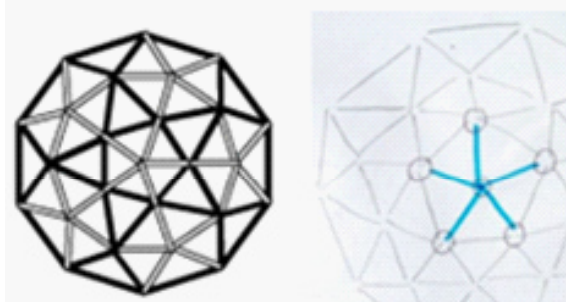

Fig. 12: Making the ceiling 

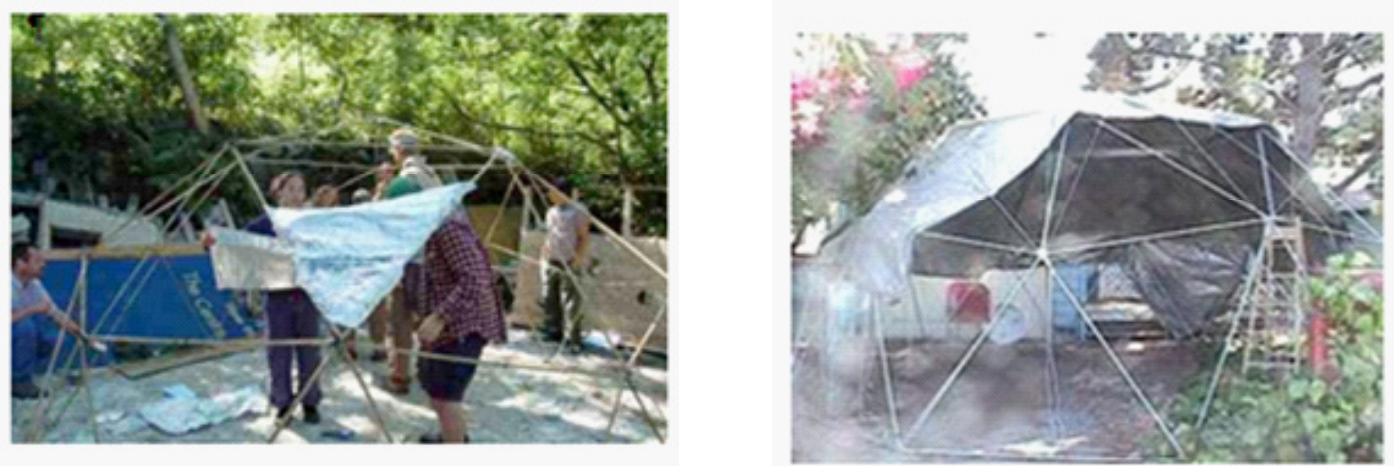

Fig. 13: How to cover the structure with aluminum foils

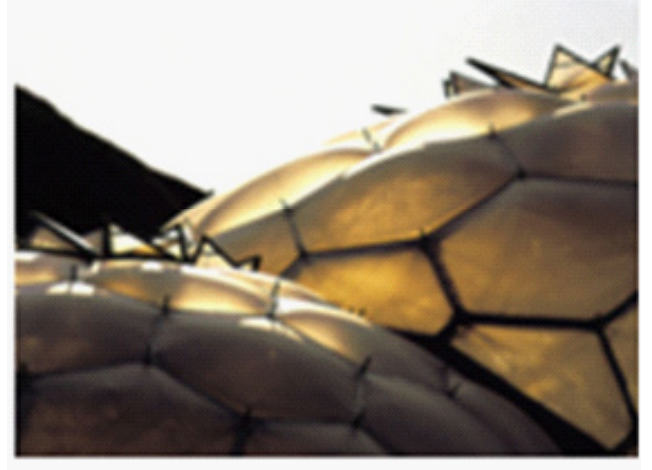

Fig. 14: Eden garden of plants

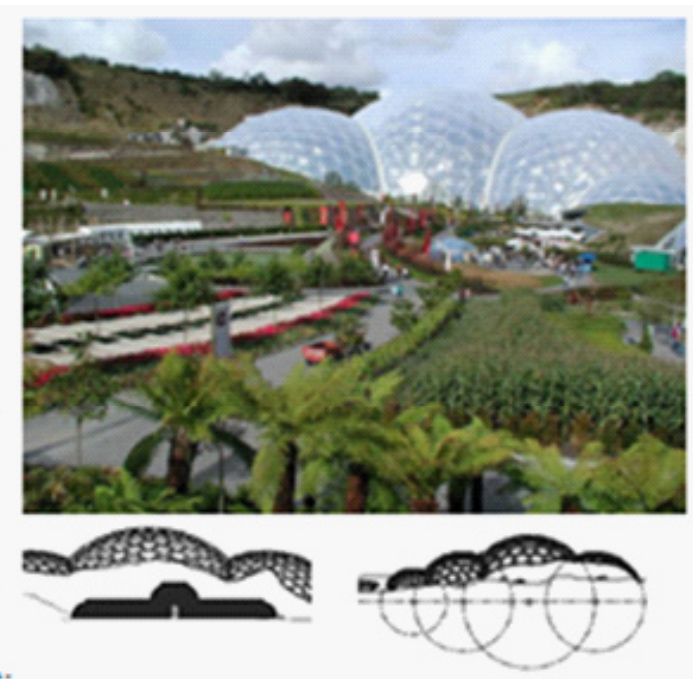

Fig. 15: Geometry of eight geodesic dome in Eden Garden
These spheres are in fact a maneuver to demonstrate the high efficiency of space and building materials that from the constructing view point each of them is a two layers space frame, that the first layer is a shell icosahedral geodesic, that id made of 6 corner modules that have variable sizes between 5 to 11 meters.

Each module consists of six direct pressure pipes, which are sleek and are relatively small and portable. This makes any 6-sided installation on the ground to be placed in its original position and to be connected easily to the 6-sided around with joints (nodes) steel.

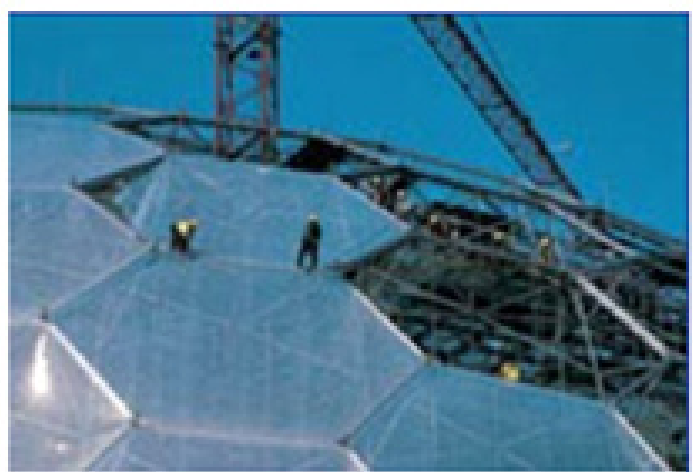

\section{Monkeys in the sky}

Eden's so-called 'sky monkeys' scale the Biomes and install the ETFE panels

Fig. 16: Connecting supportive panels 
The top layer can be installed to second layer with diagonal elements with circular hollow section.

The static behavior of this structure is guaranteed by the shell behavior and threedimensional space cross domes. This behavior is by the upper and lower layers hinge to each other that these parts are fixed to a narrow strip of reinforced concrete foundations around the sphere and then it would get to the back layer.

The sphere foundation (geodesic domes) is of a reinforced concrete that goes around the spheres and gets to the back wall of the foundation.

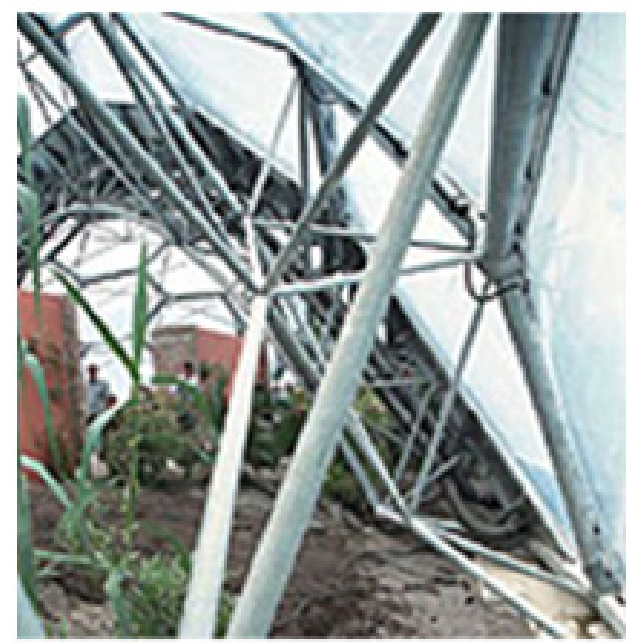

Fig. 17: The stability of medulla

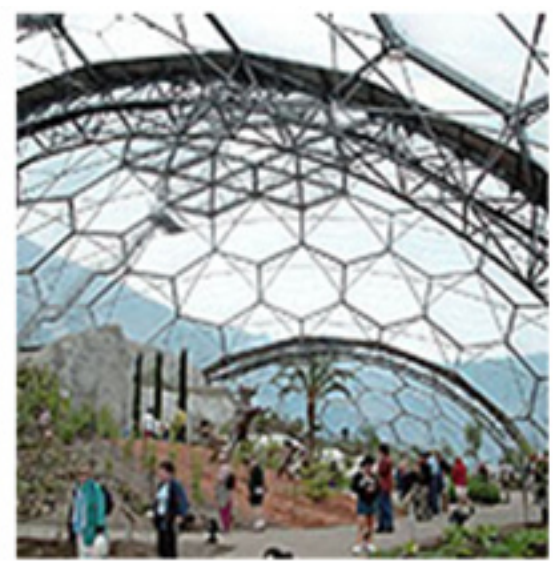

Fig. 19: Inside the sphere, Tropical Greenhouse
This foundation is about 2 meters wide, 5.1 meters thick and about 858 meters in length.

Movement of the sun has determined the exact location of these spheres, it showed a highlevel technique where the structure will be the main beneficiary of passive solar energy.

Architects of the Project have doubled the exploitation of solar energy into spheres by the Ethylene tetra-fluoride Ethylene. ETFE is completely transparent against a wide spectrum of sunlight and is considered as a very light material for utilization in structures and buildings which are designed to be quite minimal and at the same time very convenient.

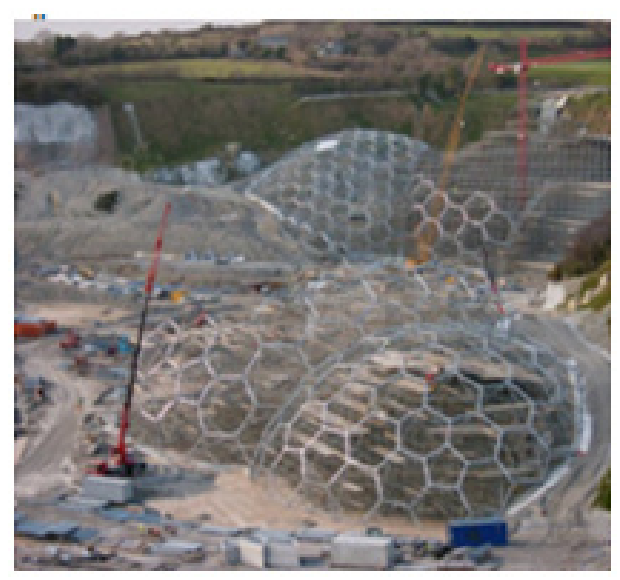

Fig. 18: Working equipment in the site

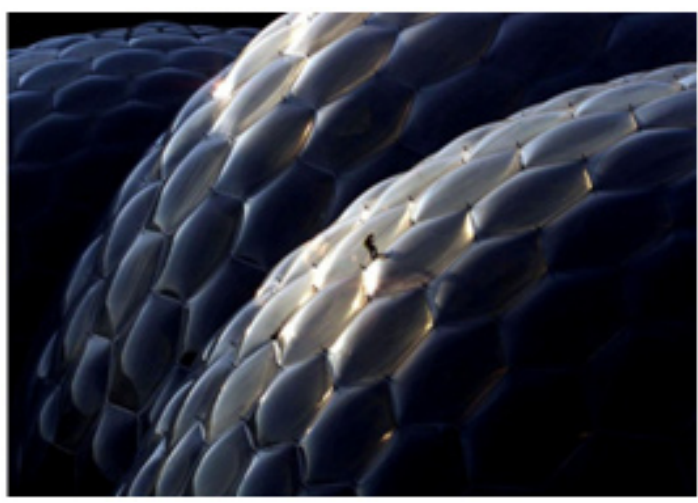

Fig. 20: Cover of the building is Ethylene tetra-fluoride, ethylene 

Ethylene:

Features of Ethylene tetra-fluoride - $\quad$ Lightness (it is $1 \%$ of the same load with glass)

- High transparency against ultraviolet radiation

- Resistant to erosion from sunlight

- Repellency of dust

- High isolation characteristics of the glass

- Recyclability

- The ability to load up to 400 times of its own weight

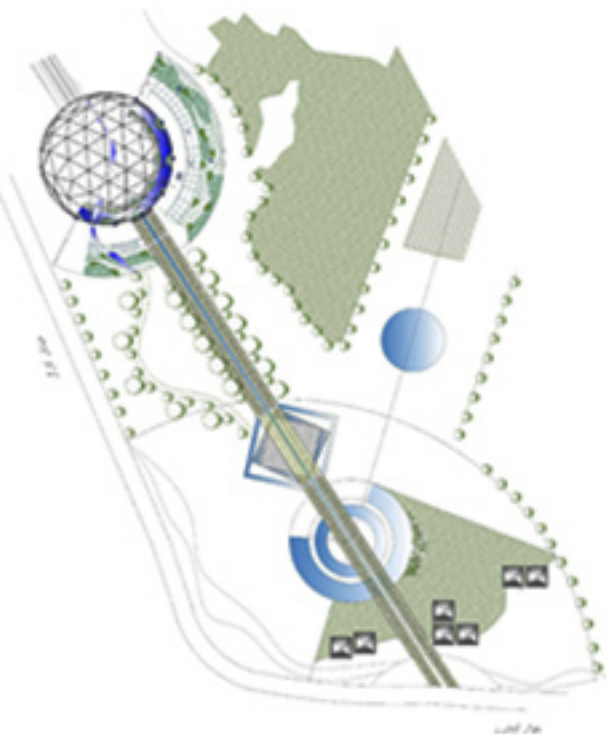

Fig. 21: Site plan of research center, Author

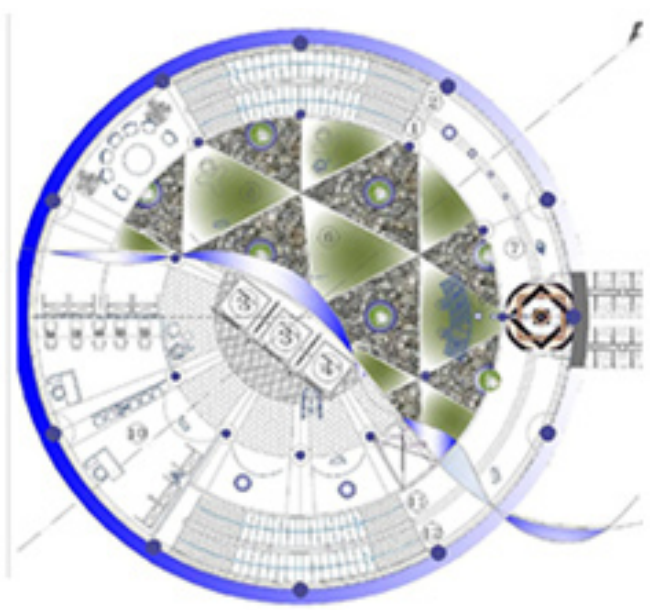

Fig. 23: Ground floor, Author
With this coverage we can make sure that plenty of day light passes of sphere coverage and feed the plant life inside. Since each frame is covered in the 6-sided three-layer, it is possible to preserve the heat of sphere.

Dead load of ETFE is $1 \%$ of the dead load of each piece of glass is less of its size, and also it is strong, antistatic and recyclable so as a tangible example of sphere targets on energy awareness is a reality now. (Hugh, 2003)

Phase one of the project that is the visitor center opened on 15 May 2000 and the final count of visitors has almost reached, 491213 people on 7 January 2001, the total annual estimate of 750,000 visitors to the site on March 17, 2001 in fact, about 1.91 million people the from the birth of the project in March 2001 have visited it.

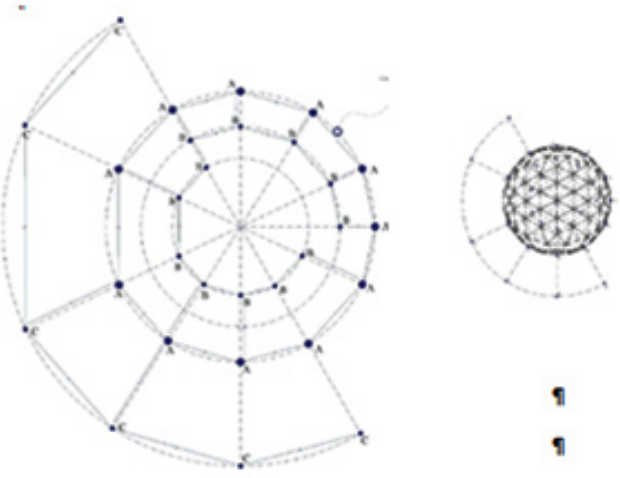

Fig. 22: Diagram of the structure

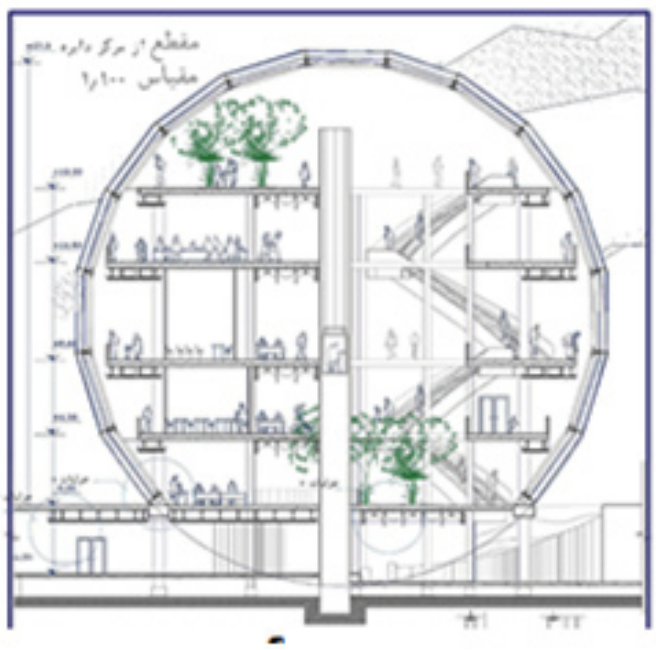

Fig. 24: Section of the project, Author 


\section{Design a research center with geodesic structures}

The project presented by the author in the design-technology (3) undergraduate senior technical architecture College of Fine Arts, University of Tehran. In structural design of this project geodesic dome is used.

The dome's construction method is explained before it is used like the geometry soccer ball.

The dome relies on its 4.3 and 5 points that these five points are sitting on a concrete ring followed by the columns of $A$ that transmit the load to the ground, it is shown in the following figure. As mentioned, the volume of a geodesic dome structure which is $4 / 3$ of the ring itself sits on a ring of reinforced concrete, $85 \mathrm{~cm}$ concrete columns help the ring to transmit the load to the foundations. Floors are made of some concrete slab that with concrete columns cooperation carry their load to foundation.

The main idea of the design was carried out according to the main objectives of the curriculum and its emphasis on sustainable architecture in this area. In designing we the generality to detailed was more in consideration and also we cared about the potential of the construction to be able to be used as a real structure in building.

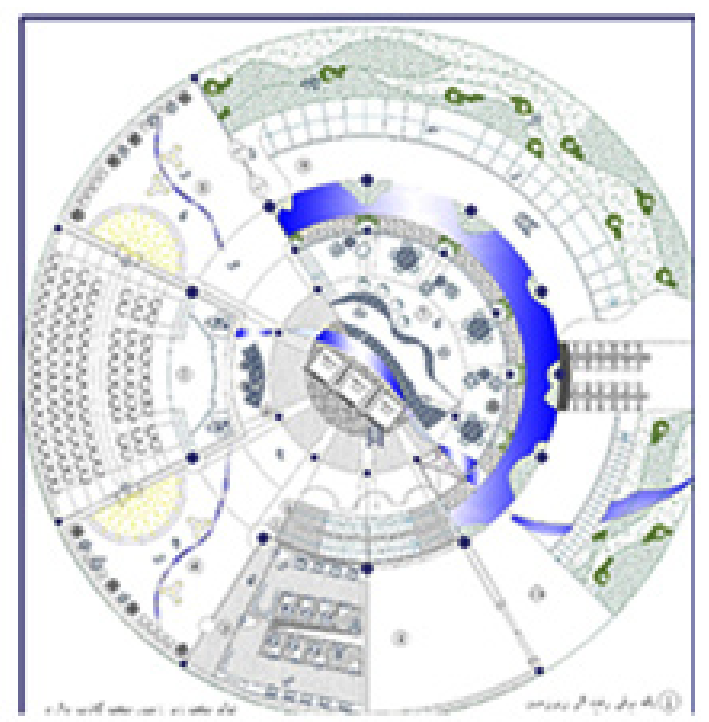

Fig. 25: Basement floor, Author
Since the planet and sustainable architecture were of the main goals of this building basic idea was based on the volume reminiscent of Earth, a geodesic dome of that is $4 / 3$ (three quarters) of its all parts on the ground, the best answer was concept 2.

Spaces within the complex: Designing Interiors were presented based on physical program, because visitors of the complex are set at three social class, inner spaces were organized in order of public to private:

- $\quad$ The ground floor and basement for public visitors of general age and social class

- $\quad$ First and second floors for professional enthusiasts

- $\quad$ Third and fourth floors for specialists in new construction technologies

That of course for the knowledge of ordinary people public facilities through the glass elevators to the upper floors and reach the last floor of the dome (the experts) was provided to the public and as it is proved by evidence this will not make any disturbance to the work of the experts and professionals (pay attention to the fourth floor plan, the public space is isolated with soundless partitions from the private space)

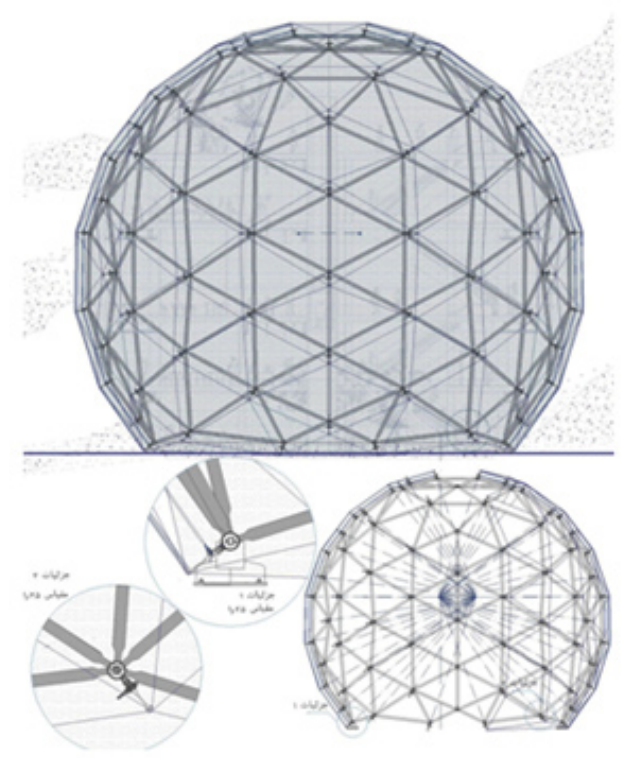

Fig. 26: Elevation and details of installing materials, Author 
We have considered an all-round void inside the complex that based on the principles of architecture a green part is considered inside this place.

Grounds of the floors are open in the corners of a size of about 1.5 meters to allow natural ventilation and heat exchange and enables more air in accordance with the principles of sustainable architecture adequate and coordinate...

Basement space has the lobby, coffee shop and sitting place, as well as an amphitheater and also their place in the auditorium. These are designed so they receive natural light and emptying of the volume of the original volume in terms of visual effect is multiplied.

Installation: In the case of heating and cooling installations there is a powerhouse of an adequate size placed in the basement that we paid attention to the access to the site in order to transport the equipment easily. A duct is predicted across for necessary crossings since we have considered a duct for the complex in second and fourth floor duct is located in the far places in the rooms. While the false ceiling of the facility is considered essential for pipelines and, of course, false ceilings with the original plan and space geometry sets quite the same regiment in designing in order not to harm the monolithic space and order.

View: View of the dome is of ethylene tetrafluoride ethylene on which protective layer prevents the penetration of ultraviolet radiation is covered. This layer turns dark in intense light and it helps regulating the amount of light into the complex. This view is double skinned that keeps the set temperature and prevent heat exchange with the outside air as an insulator acts. In designing the view of the dome we tried to completely keep the transparency in an attempt to reflect the sky on the project which will contribute to the main idea. Anti-static panels are used to avoid contamination and absorb dust particles, in this case the need to clean the panels is decreased and the climber ${ }^{1}$ will just be used for urgent cases!

\section{CONCLUSION}

In today's world creating exquisite landscapes and interesting urban design and architecture is inevitable. It is obvious that familiarity with the technology and methods of construction of geodesic dome structures such as buildings of this structure and durable can pave the way for constructing such buildings and yet keep the beautification of this places. Easing the methods of constructing and designs of such structures can be really useful for leading engineers and encouraging them to create some more of such constructions.

Since a geodesic dome uses Self-bracing triangles, it is a highly profitable structure so this causes the least use of material for its theory creating. In addition with that it meets many of visual attractions that are important in architectural design.

Designing a research center inside this volume has made this problem obvious that with using design principles all needed plans in the circle are possible to create. While view and other operational details are easy to design, so that not only the architecture and structure have been answered very well, but also absorbing a beautiful volume that also reflects the power of design and construction engineering of the country.

Generally, it should be noted that geodesic structures is a light structure that with ease of implementation and the ability to cover large spans and high strength building will make the construction unique both visually and structurally.

\section{REFERENCES}

1. Urner, K., GEODESIC DOMES THE GEOMETRY, www.neubert.net-Dr. Neubert Website, Last visited: 1/April/2016.

2. Ghorbanzadeh, M., Course notes, pamphlets of advanced building systems and construction systems classes, architectural technology graduate of Tehran University, The professor: Professor Mahmoud Golabchi, 2008

3. Wikipedia, Geodesic dome, the free encyclopedia, Last visited: 31/Dec/2015

4. Baldwin, J., Geodesic Domes, American masters, Thirteen media with impact, 2015 
5. Moore, F,. understanding structures translated by Golabchi, M,. p.67, 2008

6. Jonathan S., How to Build a (Geodesic Dome out of Cardboard), www.cat.org.uk/msc, Last visited: 31/Dec/2015

7. http://www.grimshaw-architects.com/index. html?project=6, Last visited: 31/Dec/2015

8. Hugh, P. Whalley, A., The Architecture Of Eden, Transworld Publishers, 2003 